\title{
Eruption abnormalities in permanent molars: differential diagnosis and radiographic exploration
}

\author{
J. Cohen-Lévy ${ }^{1}$, N. Cohen ${ }^{2}$ \\ 1 Dental surgeon, DFO specialist \\ 2 Dental surgeon
}

ABSTRACT

Abnormalities of permanent molar eruption are relatively rare, and particularly difficult to deal with,. Diagnosis is founded mainly on radiographs, the systematic analysis of which is detailed here. Necessary terms such as non-eruption, impaction, embedding, primary failure of eruption and ankylosis are defined and situated in their clinical context, illustrated by typical cases.

KEYWORDS

Molars, impaction, primary failure of eruption (PFE), dilaceration, ankylosis

\section{INTRODUCTION}

Dental eruption is a complex developmental process during which the dental germ moves in a coordinated fashion through time and space as it continues the edification of the root; its 3-dimensional pathway crosses the alveolar bone up to the oral epithelium to reach its final position in the occlusion plane. This local process is regulated by genes expressing in the dental follicle, at critical periods following a precise chronology, bilaterally coordinated with facial growth.

Unlike the third molars, in first and second permanent molars eruption abnormalities are relatively rare, estimated at $0.06 \%$ by Prece $^{25}$; Grover ${ }^{17}$ reported similar prevalence, at $0.08 \%$ for second maxillary molars and $0.01 \%$ for first mandibular molars. More recently, considerably higher prevalence rates were reported in retrospective studies based on orthodontic consultation records: $2.3 \%$ for second molar eruption abnormalities as a whole, comprising $1.5 \%$ ectopic eruption, $0.2 \%$ impaction and $0.6 \%$ primary failure of eruption (PFE) (Bondemark and Tsiopa ${ }^{4}$ ), and up to $1.36 \%$ permanent second molar iimpaction according to Cassetta et al. ${ }^{6}$.

However rare, these abnormalities represent a real therapeutic challenge ${ }^{32}$ :

- situated distally and sometimes deeply, they are difficult of access for the surgeon and orthodontist; 
- as anchorage is strong, movement is difficult to control without impact on proximal teeth;

- they may fail to respond to orthodontic treatment, and may show ankylosis, to the frustration of both patient and care team ${ }^{5,22,23}$

The present article defines terminology in eruption abnormality (noneruption, retention, embedding and impaction, ankylosis, and failure of eruption), then analyzes various clinical situations and associated radiographic signs. Complementary examinations (panoramic X-ray, lateral teleradiography, CT or cone-beam CT cross-sectional imaging) should be systematically analyzed, without overlooking their shortcomings.

\section{TERMINOLOGY AND DEFINITIONS}

Certain of the definitions used by the French health authority (Haute Autorité de Santé, formerly ANAES ${ }^{1}$ ) were adopted and explained by Favre de Thierrens et al. ${ }^{13,14}$ :

- an "unerupted" tooth is a mature tooth that has failed to erupt by the physiological date, with a pericoronary follicule lacking communication with the oral cavity. An unerupted tooth may or may not be covered by bone tissue, but is totally covered by the oral mucosa;

- a "retained" tooth is an immature tooth in which eruption is hindered but evolutive potential is conserved. Radicular edification is not arrested (open apex). With maturation, "retention" becomes inclusion or embedding;

- an "impacted" tooth is a mature tooth, which may be unerupted or not, but in which eruption is arrested by an obstacle. Once the obstacle has been lifted, the tooth conserves evolutive potential and can resume eruption;

- a "disinvested tooth" is a tooth that had been impacted but becomes exposed to the oral cavity.

The World Health Organization (WHO) drew up its Classification of Diseases and Related Health Problems (ICD); ICD-10 is the $10^{\text {th }}$ version. It defined "embedded tooth" as a tooth that has not erupted into the arcade despite absence of obstacle, and "impacted tooth" as a tooth hindered by an obstacle.

Raghoebar27,28 gave definitions based on etiology:

- "impacted" teeth, blocked in eruption by a mechanical obstacle, without alteration of the eruption process as such, which continues once the obstacle has been lifted;

- teeth in which the eruption process is impaired. Such "retention" may be isolated or associated with other genetic abnormalities. There are 2 associated clinical entities: ankylosis (OMIM \#157950) and primary failure of eruption (PFE), a genetic disorder (OMIM \#125350).

According to Raghoebar ${ }^{27,28}$, in PFE the tooth remains in an infracrestal position, never penetrating the oral cavity; in secondary failure of eruption (SFE), eruption is interrupted supracrestally, after penetration into the cavity. In recent publications, the terms "primary" and "secondary" have given way to "infra-/supra-crestal", which are more descriptive, free of etiological presuppositions ${ }^{31}$.

In French, however, we feel that the term "rétention" may be confusing 
and should not be used for an eruption abnormality: treatment is quite different if the tooth is "retained" by an obstacle, as could quite naturally be said in French, whereas the English term "retention" specifically implies the absence of any obstacle and rather an impaired eruption process.

Ankylosis is defined histologically as fusion of the cementum with the alveolar bone in at least 1 zone, which thus lacks any ligament space. Etiology is generally traumatic and ankylosis in a tooth thus tends to be isolated.

In PFE, there is no primary ankylosis, but rather a disorder of the eruption mechanism, totally or partially preventing tooth progression. In case of early extraction, PFE teeth show normal mobility. The specificity of
PFE is that all the teeth distal to the first to be affected are also involved; they do not respond to orthodontic treatment, and undergo secondary ankylosis ${ }^{15,16,26,31}$.

Isolated ankylosis and PFE are very difficult to differentiate, especially in young patients ${ }^{31-33}$, but every effort should be made to do so, as treatment is radically different ${ }^{31,34}$, despite the similar clinical aspect of infra-occlusion. In PFE, all the distal teeth are affected, cannot be mobilized, and undergo secondary ankylosis; in isolated ankylosis, by contrast, the distal teeth respond to orthodontic displacement, and orthodontic treatment is feasible (perhaps with extraction of the ankylosed tooth, or mobilizing only the adjacent teeth) ${ }^{15,16,26,31}$.

\section{GENERAL HISTORY}

Eruption abnormalities may be isolated or associated with other disorders, explored by the medical questionnaire and history-taking, looking for endocrine disorders (hypopituitarism, hypothyroidism, parathyroid pathology), phosphocalcic metabolism disorder (rickets, Albright's disease), and signs of genetic abnormalities that may be associated with generalized dental retardation:

- cleidocranial dysplasia (sequela of cleidocranial dysostosis or MarieSainton syndrome, now classified as OMIM \#119600);

- mucopolysaccharidosis;

- Gorlin-Goltz syndrome (OMIM \#109400);

- GAPO syndrome (growth retardation, alopecia, pseudo-anodontia

\begin{abstract}
and optic atrophy) (OMIM \#230740);

- osteopetrosis or osteosclerosis (also known as marble bone disease: OMIM \#259700 \#259710 \#259730 for recessive forms, and \#166600 \#607634 for dominant forms).
\end{abstract}

Familial history of posterior tooth eruption disorder should be investigated (siblings ${ }^{6,7,12}$, parents $\left.{ }^{6,7,19,29-31}\right)$, as PFE is often associated with non-syndromic genetic abnormalities (familial in $10-40 \%$ of cases $\left.^{4}\right)$. Mutations or single nucleotide non-functional polymorphisms of the gene coding for parathyroid hormone 1 receptor ${ }^{24}$ (PTH1R, on 
chromosome $3^{10,15,16,31}$ ) have been reported $^{31}$. Transmission is autosomal-dominant with incomplete penetrance 2,4 .

\section{SYSTEMATIC RADIOGRAPHY ANALYSIS}

In a clinical situation with missing molars, various diagnoses are to be excluded: general retardation of dental age, locally retarded eruption (due to an obstacle, or not) or one or more ageneses (fig. 1).

Panoramic radiography is essential, to inventory dental abnormalities (of form, position and structure), compare progression between left and right sides, and give a general impression of the morphology and texture of the bone parts.

Visual assessment systematically comprises:

- Number of teeth, and their relations (fig. 1).
Other associated dental abnormalities (class-III malocclusion, deciduous molar ankylosis) have also been reported in $\mathrm{PFE}^{3,31,36}$.
- Germ orientation (coronary mesioversion or straight axis), projecting the eruption pathway to check for obstacles. The developmental axis of the mandibular molars is determined by the inclination of the dental lamina, which curves inward at the mandibular angle during growth: PFE or ankylosis may often be suspected is eruption is arrested despite a straight axis and no obstacles.

- Germ maturation stage, notably apical closure.

- Root morphology: incipient cubitus (dilaceration), which may be of negative prognosis, indicating

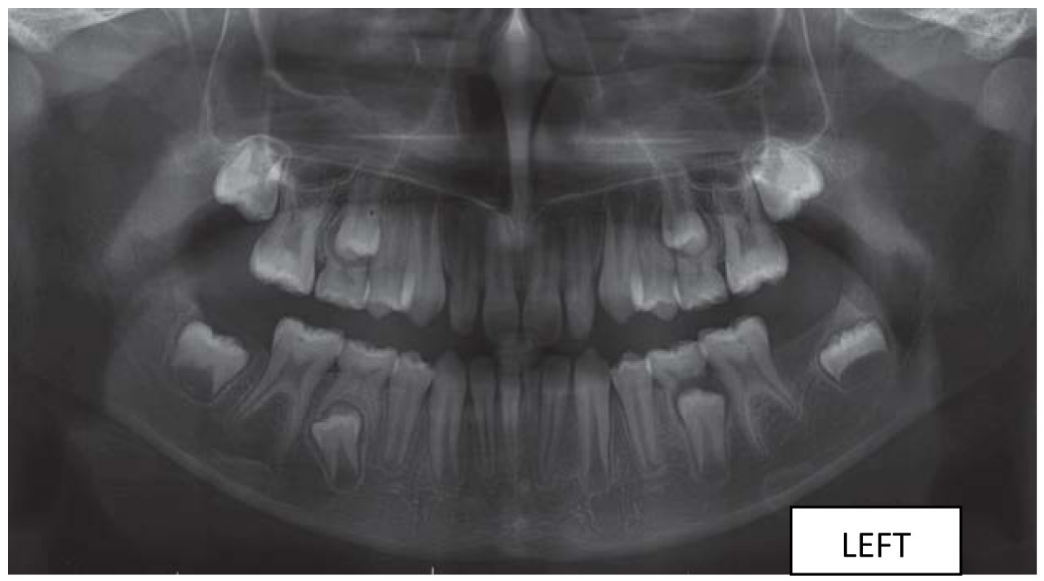

Figure 1

Panoramic X-ray showing various abnormalities: agenesis of 37 and 47 , while 38 and 48 germs are present with a distal diastema at 36-46 (which show taurodontism), agenesis of 31 with persistence of 71, and relative microdontia of 12 and 22. 
arrested eruption. Such roots develop "hookwise", to get around anatomic obstacles such as the basilar edge or sinus roof. A tooth is said to be "furrowed" if it is in direct contact with the mandibular canal, which leaves its trace during edification, and "obstructed" when it bends around the canal. CT or MRI should be prescribed in case of doubt, to follow the trajectory of the canal, slice by slice.

- Examination of the occlusion plane, as lateral open-bite is systematic in PFE ${ }^{19,26 .}$

- Examination of the regularity of the desmodontal space and lamina dura and the follicular sac, and also of the clarity of the enamel contour (screening for coronary resorption).

- Assessment of dentine density, especially in the cervical region and furcation (screening for replacement resorption or ankylosis).

Radiographic diagnosis of ankylosis in multi-root teeth is made very difficult by the superimposition of the structures: the ankylosed surfaces of the buccal and lingual or palatine regions are not visible; moreover, ankylosis may be of only a few millimeters, undetectable on X-ray, even on periapical views or CT.

\section{OBSTACLES}

Various mechanical obstacles along the eruption trajectory can be identified on panoramic X-ray:

- one or more extra germs;
- odontoma (in this location, a supernumerary paramolar ${ }^{11}$ or distomolar ${ }^{20}$ tooth);

- tumoral or pseudotumoral proliferation; - cyst.

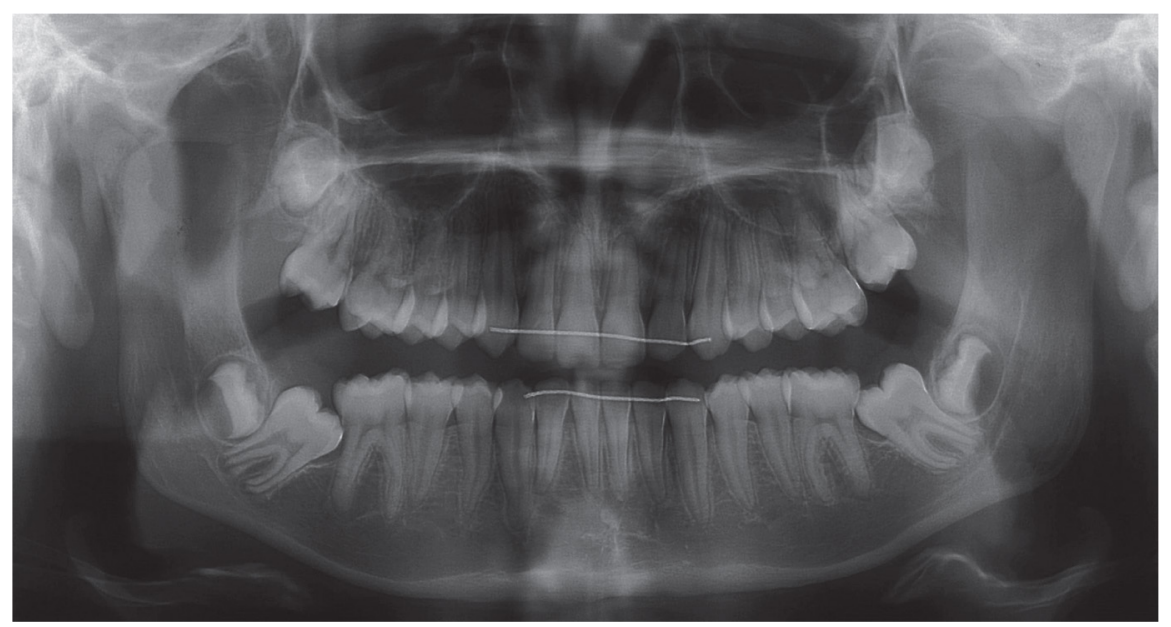

Figure 2

Posterior crowding (interception of mandibular crowding by lip-bumper), with severe coronary mesioversion of 37 and 47 germs. 


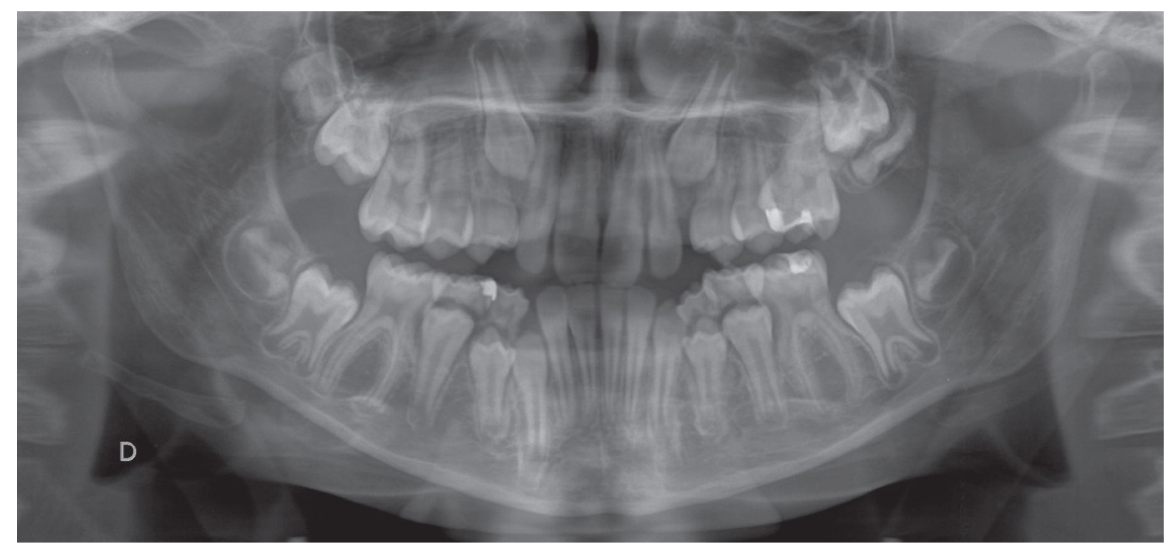

Figure 3

Delayed intra-alveolar growth of 27 compared to 17, with atypical shape and position of 28 germ.

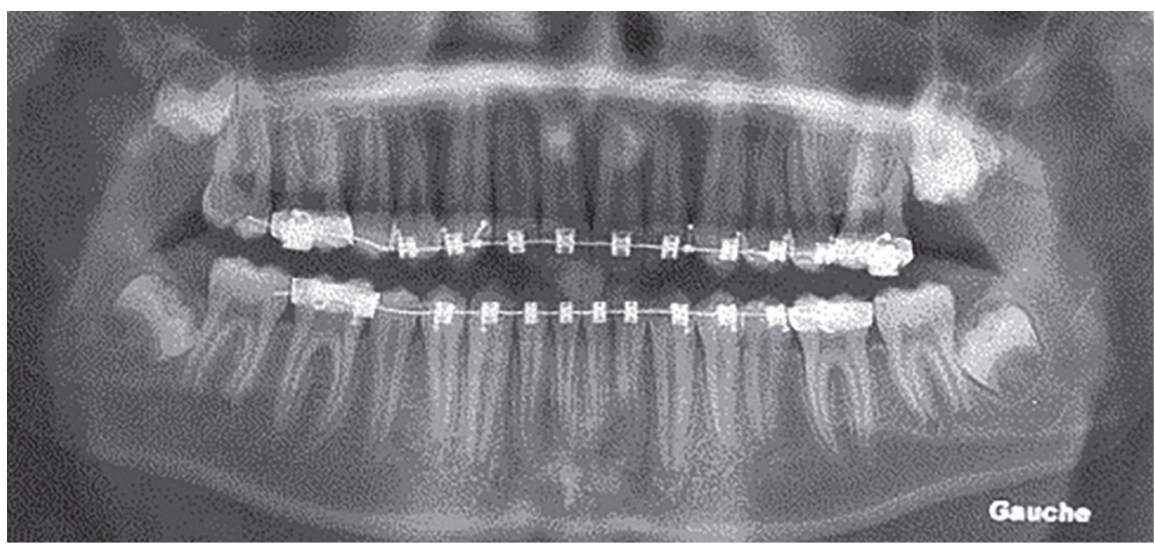

Figure 4

Multi-bracket treatment; delayed growth of 27. On panoramic view, increased dental density adjacent to 27, which is still positioned high in the left maxillary tuberosity suggesting superimposition of 27 and 28 germs.

Also frequently encountered are:

- abnormal second molar germ inclination in mesioversion, typically associated with posterior crowding; the germs are blocked under the distal first-molar corono-radicular concavity (fig. 2);

- morphologic and/or positional abnormalities of the third molars with respect to the second (flat "pancake" or "banana" wisdom tooth).
In figure 3 , the germ of 28 is positioned occlusally with respect to 27 , with a clear boundary between the two (slight follicular sac hypertrophy), making them easily distinguishable.

Figure 4 shows superimposition of the 27 and 28 germs within the maxillary tuberosity (increased molar density as compared to the right side), requiring imaging on $\mathrm{CT}$ (figure 5).

Finally, fibrous or thick gum tissue may also constitute an obstacle. This 


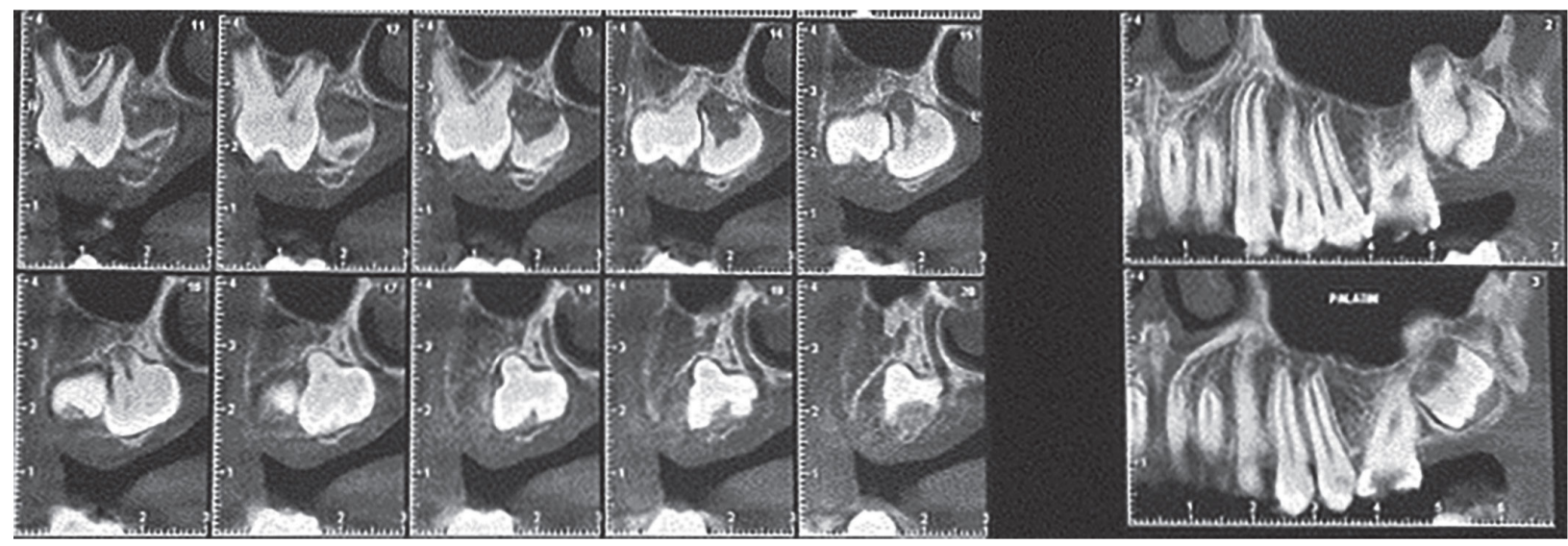

Figure 5

CT imaging (DentaScan TM) of same patient, with curvilinear reconstruction. The 27 and 28 germs are more or less in the same horizontal plane, with the second molar pushed back occlusally toward the palatine side.

is not seen on radiography, as the tooth is submucosal. A simple incision frees the crown (as seen in figures 6 and 7ab), and the tooth may then grow spontaneously.

Delayed eruption is found in hereditary gingival fibromatosis
(OMIM \#135300, \#611010, \#609955, \#605544), in which eruption should be monitored and gingivectomies may be performed. A genetic abnormality, called Rutherfud's syndrome $^{18}$ (OMIM \#180900), associating multiple impaction and gingival

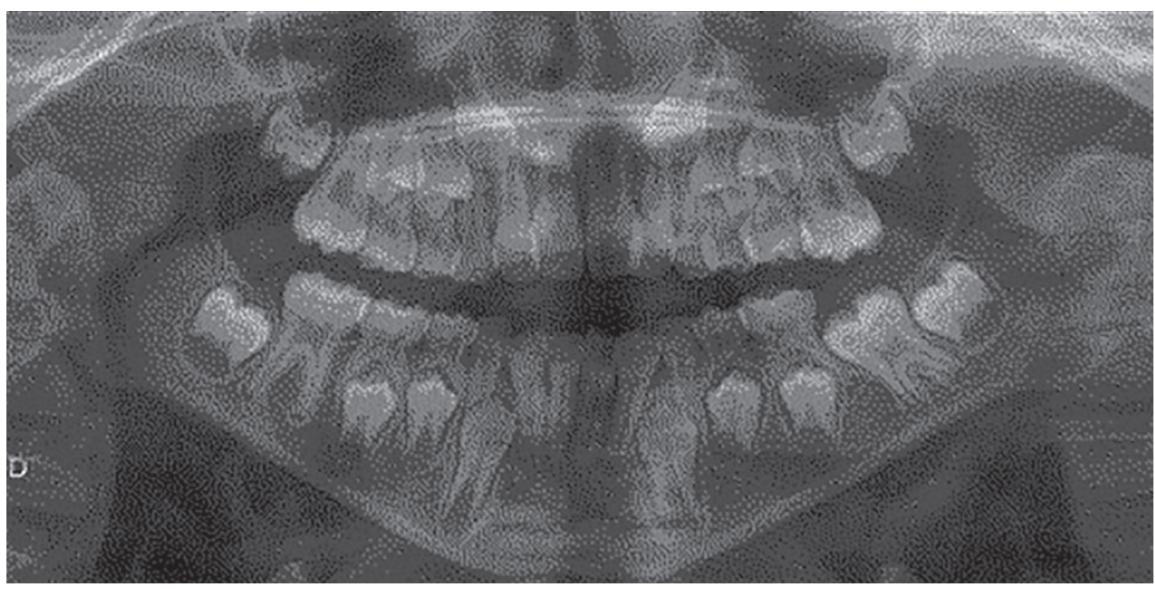

Figure 6

Panoramic view of 8 year-old patient. Delayed eruption of 36 compared to right side, which is infrapositioned in slight coronary mesioversion (2 year retardation). Incipient egression of 26. Radiography shows no visible obstacle; the crown has grown beyond the alveolar bone and is submucosal. No other abnormalities; second molar germs are symmetrical. 


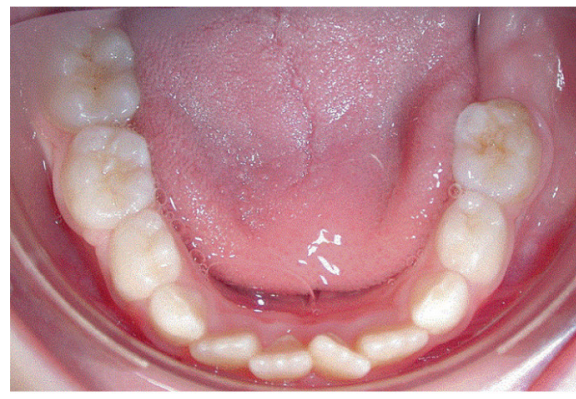

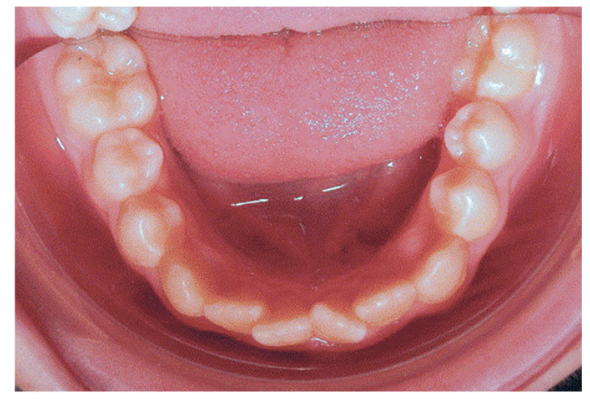

b

Figure $7 a$ and $b$

36 has grown after mucosal release. Without treatment, it remains slightly lingual and rotated. Note isolated enamel hyperplasia in 75.

hypertrophy, was reported by Houston in 1966.

Some immunosuppressors, such as cyclosporin (prescribed, for example, after heart or kidney transplantation), may induce severe gingival hypertrophy. In children, they may delay eruption or cause eruptive cysts ${ }^{37}$, treatment of which associates surgery (cold instruments or CO2 la- ser), antibiotic therapy and reinforced plaque control.

Radiography serves to locate and precisely describe the obstacle, especially when surgical resection is required, and also enables planning of the traction axis and choice of anchorage (molar fixation position, elastic force vector, application point, etc.).

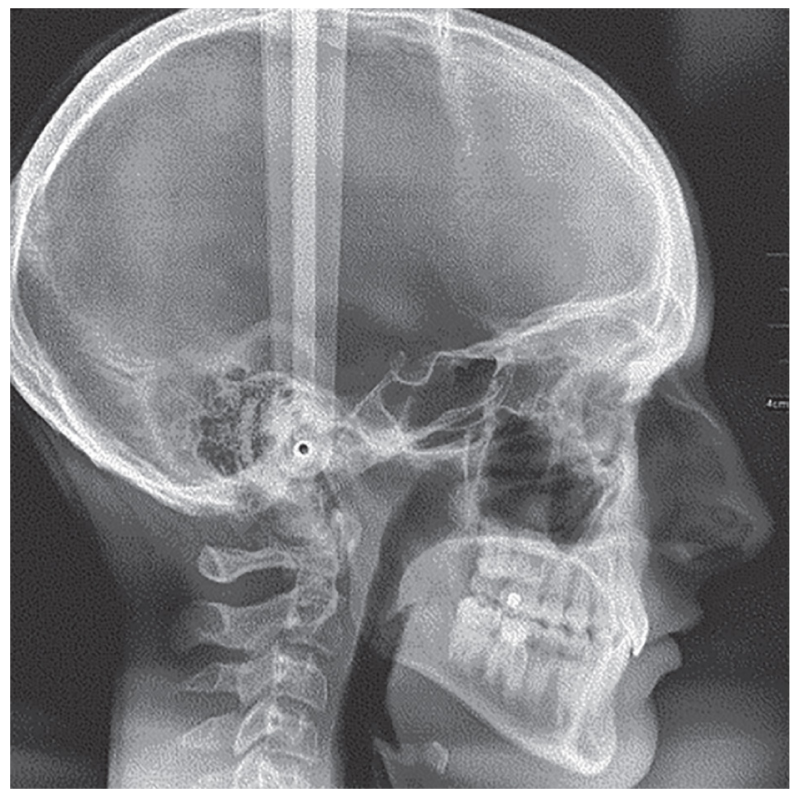

Figure 9

Lateral teleradiograph: determining the traction axis. which show a single root canal. 


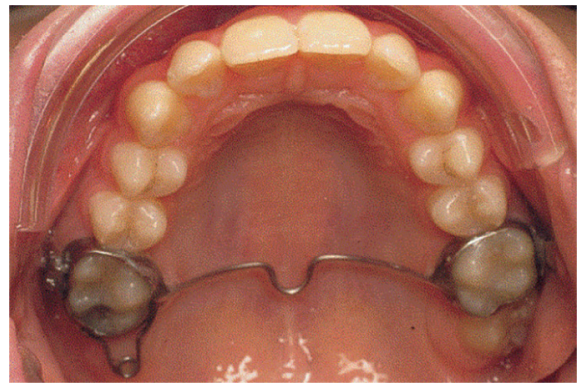

Figure 10

Anchorage system to expose impaction of 17: transpalatal arch welded onto 16-26 bands, with distal loop for metal connector.

The mechanical system put together for the next case (figures 8 and 9) aimed to distalize the coronary part of 17 , freeing it from the concavity of 16, before performing guided extrusion toward the occlusal plane. The first movement had thus to be more or less horizontal: including an extrusion component would only force the second molar against the distal side of the first molar.

Thus, only a panoramic view and lateral teleradiograph were needed.

\section{ERUPTION FAILURE $15,16,21,26,31$}

Based on the initial description by Profitt et al. ${ }^{26}$, Lyczek and Antoszewska $^{21}$ gave a radiographic description of "resorption chimneys", typical of PFE: fairly large radiolucent areas adjacent to the crowns of teeth with arrested development, indicating normal bone resorption (limits of the follicular sac). Other signs should be systematic in PFE: normal eruption of anterior teeth, and absence of obstacles on the molar eruption path, in one or more quadrants.
The surgeon releasing the molar was instructed:

- to bond the metal traction button to the occlusal side, as mesially as possible;

- and to attach the metal connection to the distal loop of the welded anchorage (transpalatine arch on molar bands, to be completed by a multi-bracket system planned secondarily (fig. 10)).

Eruption extends to the occlusal position, in contact with the antagonist tooth, and posterior open bite should thus be seen as an eruption abnormality. In a dysfunctional context, lingual interposition may constitute an obstacle, and the teeth will respond well to orthodontic treatment.

However, differential diagnosis should be considered, as ankylosis may also occur late, after molar eruption into the oral cavity; the tongue may have filled the space only secondarily, as the open-bite worsened. If clear radiographic signs are lacking, a percussion test may be performed, as the crown is easily accessible.

As described above, PFE was frequently associated with class III malocclusion and other abnormalities such as deciduous tooth ankylosis or hypodontia.

Frazier-Bowers et al. ${ }^{15,16}$ distinguished 2 types of PFE:

- type I, undifferentiated: all affected teeth show similar deficiencies;

- type II, differentiated: distal teeth show rather greater eruption potential, or a different growth potential, although without reaching a 


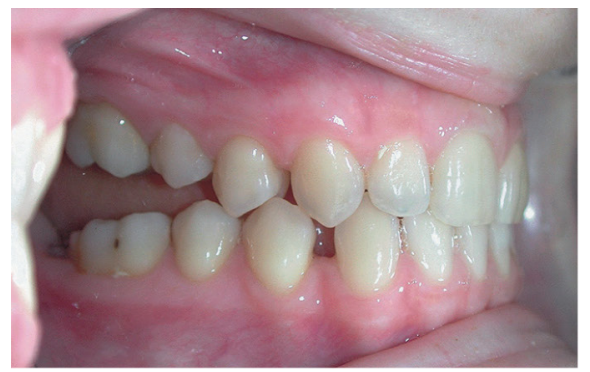

a

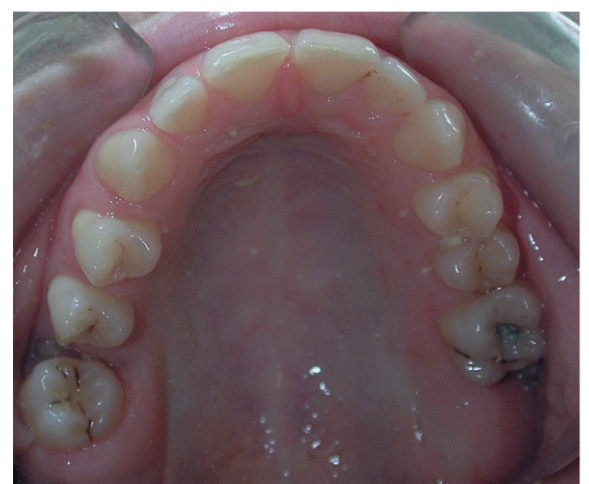

C

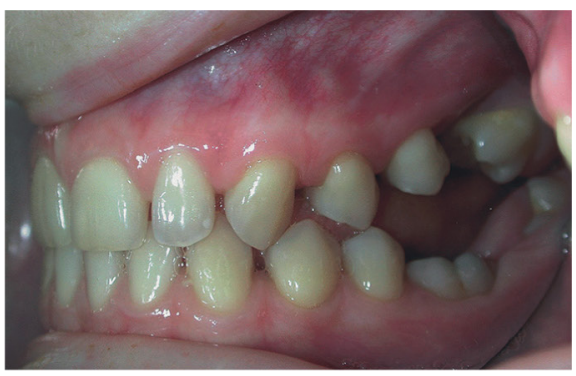

b

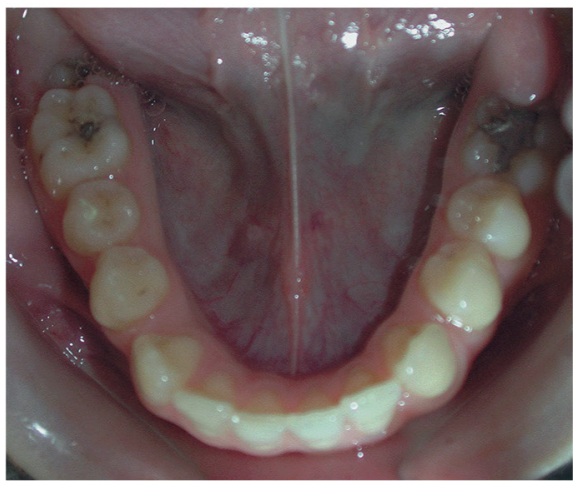

d

Figure 11

a: Right occlusion; b: Left occlusion; c: Maxillary occlusion view; d: Mandibular arcade.

functional position in the occlusion plane.

The case of two sisters (fig. $11 \mathrm{a}, \mathrm{b}$, c, d and fig. 12 a, b, c for the younger; fig. $13 \mathrm{a}, \mathrm{b}$ and fig. 14 for the elder) is especially typical: the younger had no orthodontic treatment, and showed severe PFE in all 4 quadrants; the elder underwent segmental osteotomy to try to correct left infra-occlusion (see remains of osteosynthesis material); the affected maxillary teeth were probably extracted and replaced by non-functional implants, while there was recurrence of asymmetry and infra-occlusion.

Orthodontic treatment, and especially the use of continuous arches, is contraindicated in PFE, as these teeth systematically develop anky- losis and thus behave like absolute anchorages: there is no way of positioning the affected molar, and the attempt would merely mobilize all the other teeth to intrude and heavily lean towards the affected molars trying to position these teeth orthodontically would just make matters worse ${ }^{3}$.

In PFE, first molars spontaneously develop ankylosis over time, without orthodontic traction. All distal teeth are affected by PFE, even if some seem to show eruptive potential, as in the "differentiated" form. As Profitt said in $1982^{26}$ and Rhoads and FrazierBowers repeated in $2013^{31}$, teeth affected by PFE may at most be displaced 1 or 2 millimeters, far from reaching the occlusion plane before ankylosis sets in. 


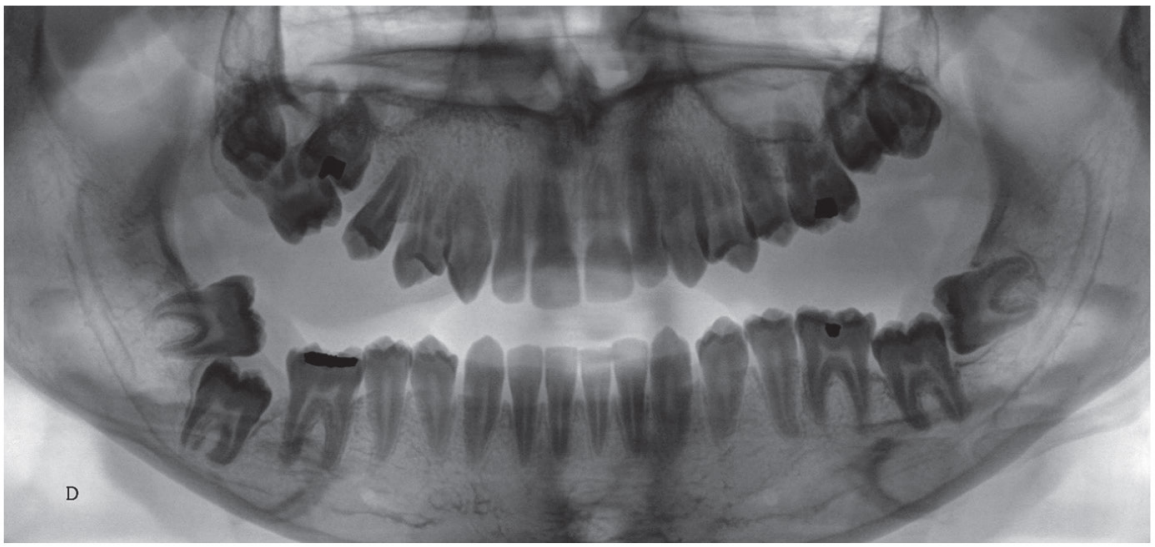

a
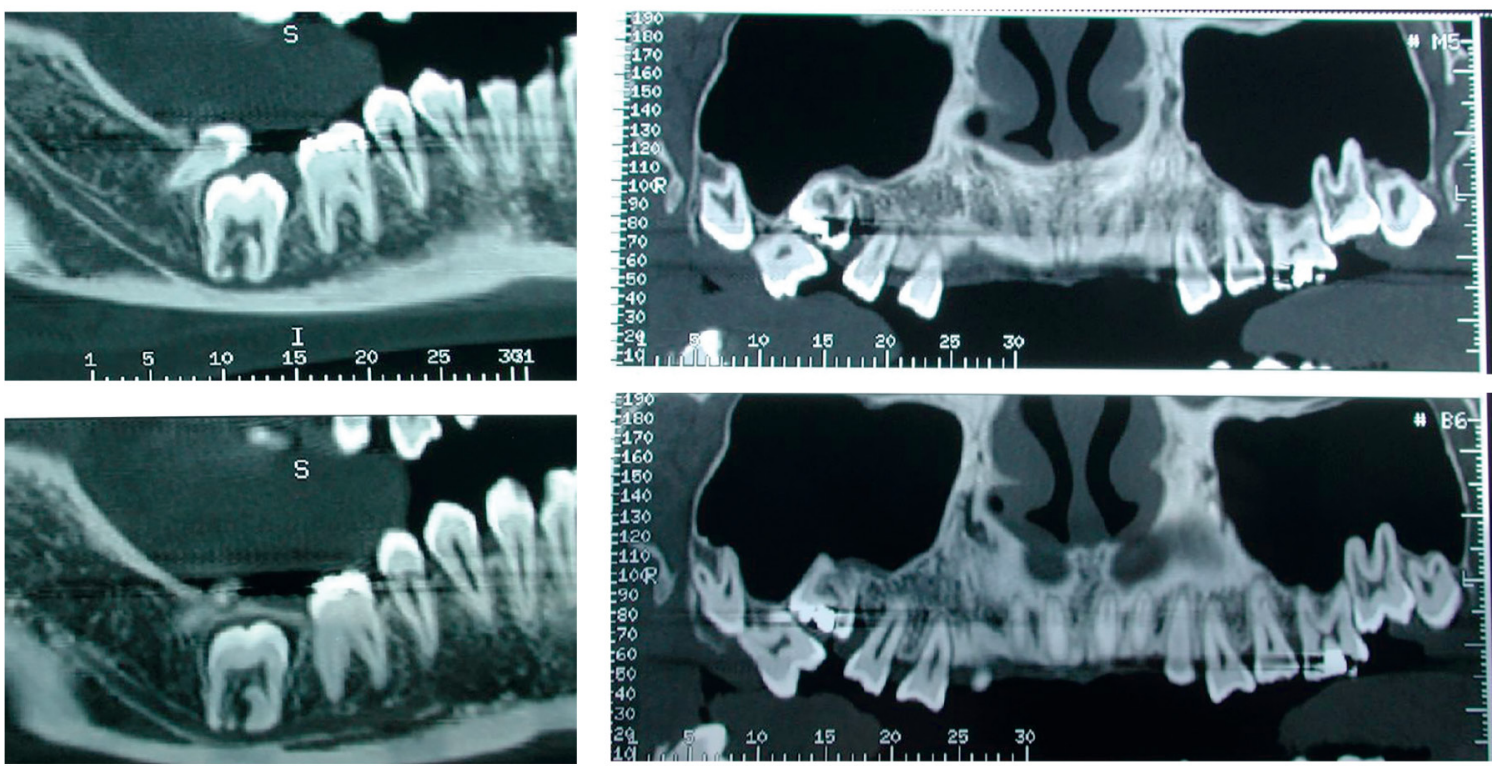

b

C

Figure 12

a: Panoramic X-ray in positive mode, showing replacement ankylosis areas at the furcation of 47. Undifferentiated PFE affecting all 4 quadrants, with infra-occlusion from premolars to last molars; short roots overall, especially in canines. 37 and 47 show radicular dilaceration. 16 must have been functionally positioned, as it shows occlusal metallic obturation.

b: Curvilinear panoramic reconstructions (DentaScan ${ }^{T M}$ ), showing ankylosis of 47: bone trabeculae seem to involve the 47 root. Follicular sac visible and intact, testifying to apparently unimpaired bone resorption. c: Curvilinear maxillary panoramic reconstructions, showing ankylosis of 16 and 27 (loss of clear boundary between dentine, pulp and bone tissue). Antral positioning of 16 and 26: extraction risks creating oral-sinus communication.

The last case (figs 15 and 16) is of isolated ankylosis rather than PFE.
Although radiography shows up certain features, ankylosis is diagnosed clinically, by percussion test (using 


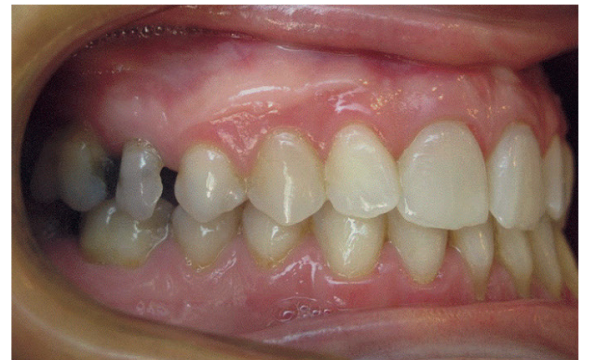

a

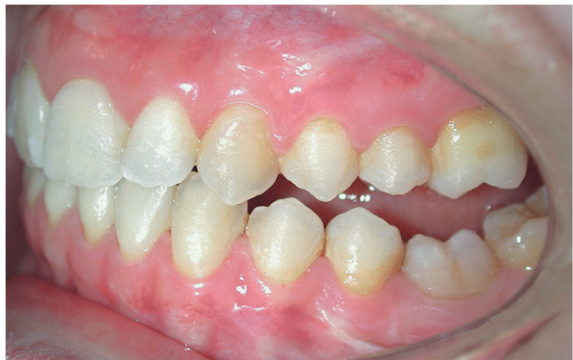

b

Figure 13

a: Right occlusal view, class I tending toward class III. b: Left occlusal view, class II, with infraocclusion extending from first premolar, especially noticeable adjacent to 36.

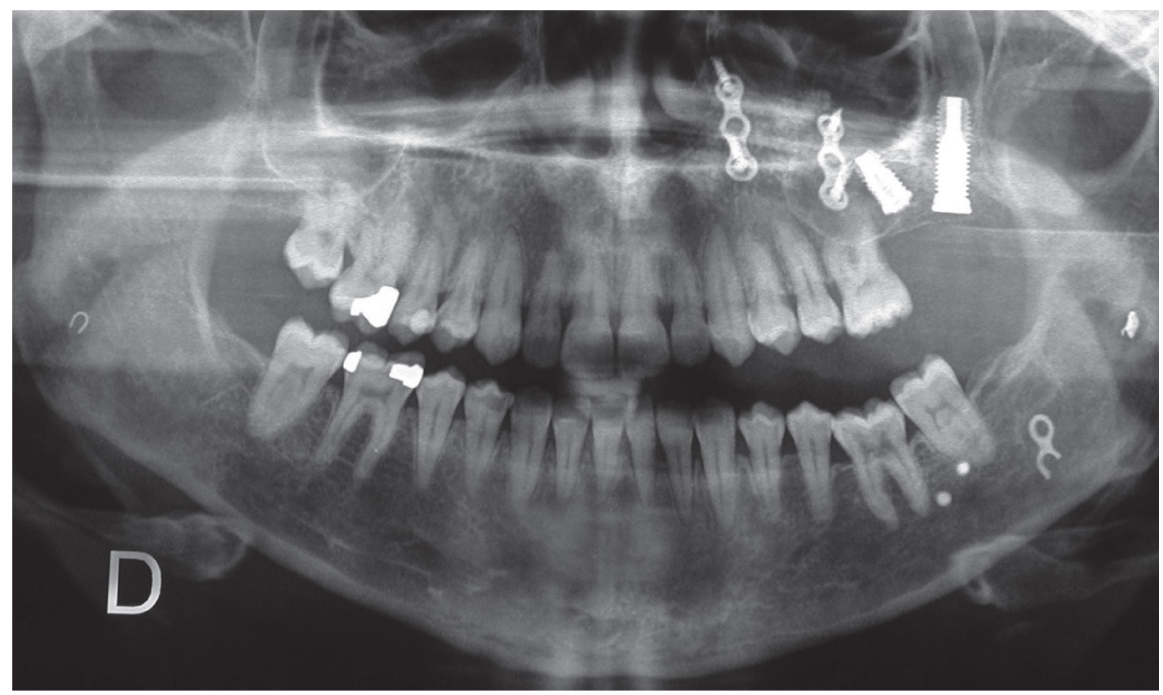

Figure 14

Panoramic view. Undifferentiated PFE involving 2 left quadrants (suspected moderate right maxillary quadrant involvement, with slight infra-occlusion of 17), with mandibular condyle asymmetry; osteosynthesis material remaining in the right and especially let mandibular angles (fragments of plate and screw), and two left maxillary osteosynthesis plates, with implant next to sinus, replacing 27, and pterygoid implant on 28.

the handle of a mirror), which produces a typical sharp, metallic sound compared with adjacent teeth, which give a dull sound. The case was treated successfully: the teeth adjacent to the affected tooth were bonded and mobilized. An occlusal composite material was bonded onto the ankylotic mandibular molar (not included within the continuous arch during treatment) at end of orthodontic treatment, to avoid any compensatory extrusion of the antagonist molar, awaiting definitive restoration (onlay). 


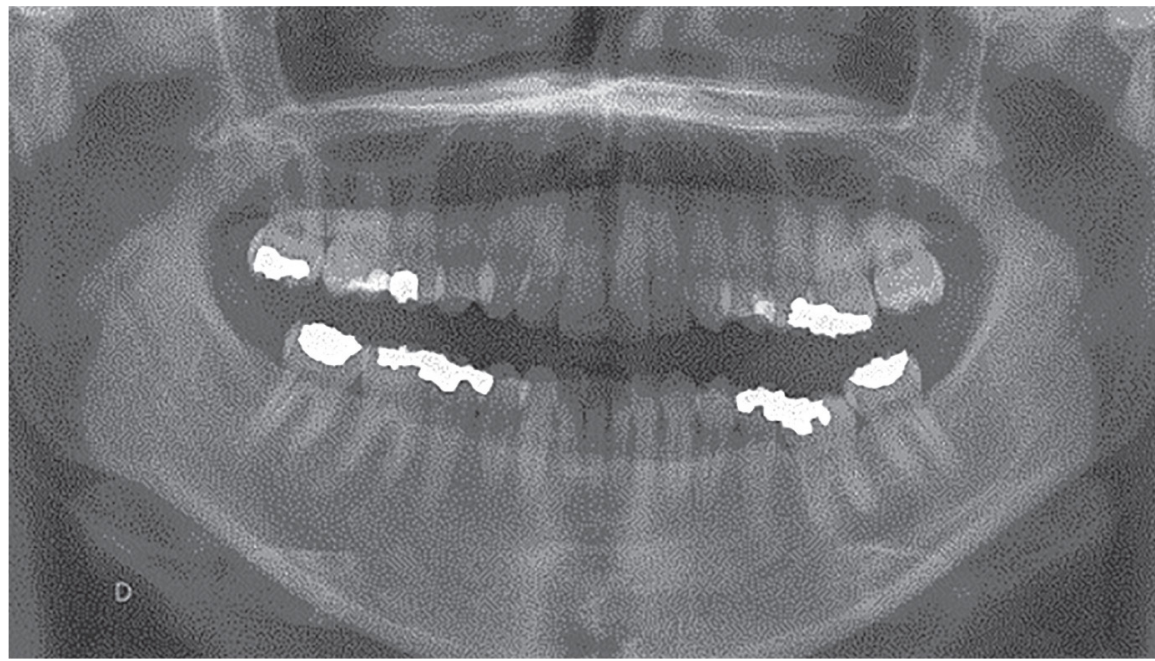

Figure 15

Panoramic view. Isolated ankylosis of 36, with characteristic reduction of dentine density at the furcation, and loss of visibility of dental ligament. Axis is straight; about $3 \mathrm{~mm}$ infra-occlusion.

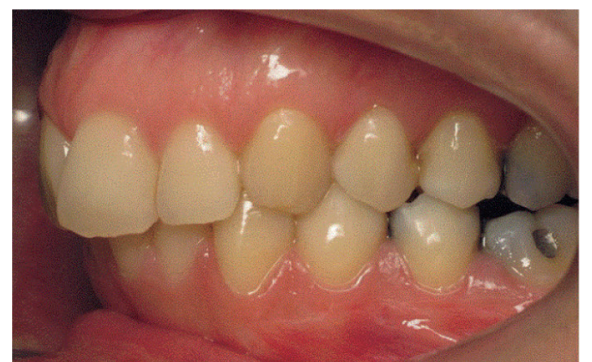

a

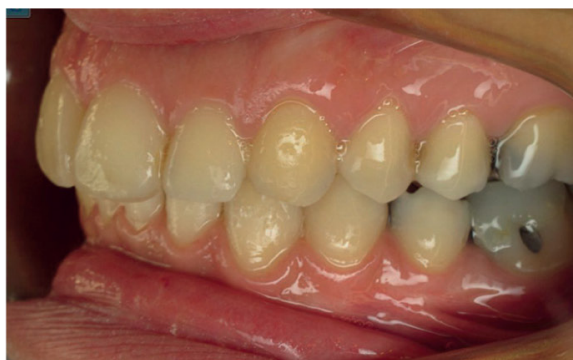

b

Figure 16

Left occlusion views (a) before and (b) after multi-bracket treatment of both arcades; all teeth were able to be mobilized (except 36, left "free" then heightened prosthetically).

\section{CONCLUSION}

Radiography is fundamental to diagnosis of permanent molar eruption disorder, but cannot be interpreted without reference to the clinical context. Differential diagnosis between ankylosis, PFE and mechanical obstacle required a trained eye and knowledge of associated abnormali- ties and the patient's history: familial history, trauma, lingual dysfunction, etc.

A diagnosis of PFE is serious, ruling out successful "classical" orthodontic treatment and requiring complex alternatives to be planned at end of growth, for rehabilitation ${ }^{8,32,34,35}$ : 
prostheses, segmental osteotomies, grafts, implants, etc.

Standardized radiograph examination and clinical percussion test can distinguish between these different entities; in a near future, however, genetic tests, notably screening for
PTHR1 gene mutations on saliva or oral epithelium samples, will help guide diagnosis.

\section{Conflict of interest}

The authors declare no conflicts of interest.

\section{INTERNET LINKS}

Haute Autorité de Santé

http://has.fr

World Health Organization, ICD-10:

http://apps.who.int/classifications/apps/icd/icd10online2007/index.htm?gk00.htm

Online Mendelian Inheritance in Man (OMIM) http://omim.org

\section{REFERENCES}

1. Agence nationale d'accréditation et d'évaluation en santé (ANAES). Indications et non indications de l'avulsion des troisièmes molaires mandibulaires. In: Recommandations et références médicales. Paris: ANAES, 1997.

2. Ahmad S, Bister D, Cobourne MT. The clinical features and aetiological basis of primary eruption failure. Eur J Orthod 2006; 28(6):535-40.

3. Baccetti T. Tooth anomalies associated with failure of eruption of first and second permanent molars. Am J Orthod Dentofacial Orthop 2000;118(6):608-10.

4. Bondemark L, Tsiopa J. Prevalence of ectopic eruption, impaction, retention and agenesis of the permanent second molar. Angle Orthod 2007;77(5):773-8.

5. Brady J. Familial primary failure of eruption of permanent teeth. J Orthod 1990;17(2): 109-13.

6. Cassetta M, Altieri F, Di Mambro A, Galluccio G, Barbato E. Impaction of permanent mandibular second molar: a retrospective study. Med Oral Patol Oral Cir Bucal 2013;18(4):e564-8.

7. Cohen-Lévy J. Ankylose des premières molaires permanentes : origine génétique ou environnementale ? Rapport de cas d'une paire de jumeaux discordants. Int Orthod 2011;9(1):76-91.

8. Cohen-Lévy J. Réflexions radio-« logiques ». À propos d'une interposition linguale. Rev Orthop Dento Faciale 2009;43:107-12.

9. da Silveira HE1, Quadros OF, Dalla-Bona RR, da Silveira HL, Fritscher GG. Dental findings in GAPO syndrome: case report. Braz Dent J 2006;17(3):259-62.

10. Decker E, et al. PTHR1 Loss-of-Function Mutations in Familial, Nonsyndromic Primary Failure of Tooth Eruption. Am J Hum Gen 2008;83(6):781-6.

11. Dhull KS, Dhull RS, Panda S, Acharya S, Yadav S, Mohanty G. Bilateral Mandibular Paramolars. Int J Clin Pediatr Dent 2014;7(1):40-2.

12. Dibiase AT, Leggat TG. Primary failure of eruption in the permanent dentition of siblings. Int J Paediatr Dent 2000;10(2):153-7. 
13. Favre de Thierrens C, Moulis E, Bigorre M, De la Chaise S. Inclusion dentaire (I). Aspects biologiques, odontogéniques, physiologiques et pathologiques. Éditions Scientifiques et Médicales Elsevier SAS, Paris. Encycl Med Chir Stomatologie 2003; 22-032.

14. Favre de Thierrens C, Geider P, Gibert P, Raynaud C. Inclusion dentaire (III). Dents incluses, au sens large. Nasogénie, sémiologie clinique et rapports anatomocliniques. Classifications internationales des dents incluses en santé publique. Éditions Scientifiques et Médicales Elsevier SAS, Paris. Encycl Med Chir Odontologie 2003;23-400 ; A-18, 31 p.

15. Frazier-Bowers SA, Simmons D, Wright JT, Proffit WR, Ackerman JL. Primary failure of eruption and PTH1R: The importance of a genetic diagnosis for orthodontic treatment planning. Am J Orthod Dentofacial Orthop 2010;137(2):160.e1-7.

16. Frazier-Bowers SA, Koehler KE, Ackerman JL, Proffit WR. Primary failure of eruption: further characterization of a rare eruption disorder. Am J Orthod Dentofacial Orthop 2007;131(5):578-e1.

17. Grover PS, Lorton L. The incidence of unrupted per- manent teeth and related clinical cases. Oral Surg Oral Med Oral Pathol 1985;59:420-5.

18. Houston IB, Shotts N. Rutherfurd's syndrome: a familial oculo-dental disorder. Acta Paediat Scand 1966;55:233-8.

19. Ireland AJ. Familial posterior open bite: a primary failure of eruption. J Orthod 1991;18(3):233-7.

20. Kaya E1, Güngör K, Demirel O, Ozütürk O. Prevalence and characteristics of nonsyndromic distomolars: a retrospective study. J Investig Clin Dent 2014 Sep 3. Epub ahead of print.

21. Lyczek J, Antoszewska J. Primary failure of eruption. Etiology, Diagnosis and Treatment. Dent Med Probl 2013;50(3):349-54.

22. Nielsen $\mathrm{SH}$, Becktor KB, Kjær I. Primary retention of first permanent mandibular molars in 29 subjects. Eur J Orthod 2006;28(6):529-34.

23. Palma C, Coelho A, González Y, Cahuana A. Failure of eruption of first and second permanent molars. J Clin Ped Dent 2003;27(3):239-45.

24. Philbrick WM, Dreyer BE, Nakchbandi IA, Karaplis AC. Parathyroid hormone-related protein is required for tooth eruption. Proc Nat Acad Sci 1998;95(20):11846-51.

25. Prece JW. The incidence of unerupted permanent teeth and related clinical cases. Oral Surg 1985;59:420- 5.

26. Proffit WR, Vig KW. Primary failure of eruption: a possible cause of posterior open-bite. Am J Orthod 1981;80(2):173-90.

27. Raghoebar GM, Boering G, Jansen HWB, Vissink A. Secondary retention of permanent molars: a histologic study. J Oral Path Med 1989;18(8):427-31.

28. Raghoebar GM, Boering G, Vissink A, Stegenga B. Eruption disturbances of permanent molars: a review. J Oral Path Med 1991;20(4):159-66.

29. Rasmussen P, Kotsaki A. Inherited primary failure of eruption in the primary dentition: report of five cases. ASDC J Dent Child 1997;64(1):43-7.

30. Reitan K. Incidence de I'inclusion dentaire au cours des traitements orthodontiques. Rev Orthop Dento-Faciale 1978;12(1):13-23.

31. Rhoads SG, Hendricks HM, Frazier-Bowers SA. Establishing the diagnostic criteria for eruption disorders based on genetic and clinical data. Am J Orthod Dentofacial Orthop 2013;144(2):194-202.

32. Siegel SC, O'Connell A. Oral rehabilitation of a child with primary failure of tooth eruption. J Prosthodontics 1999;8(3):201-7. 
33. Smith CP, Al-Awadhi EA, Garvey MT. An atypical presentation of mechanical failure of eruption of a mandibular permanent molar: diagnosis and treatment case report. Eur Arch Paed Dent 2012;13(3):152-6.

34. Suri L, Gagari E, Vastardis H. Delayed tooth eruption: pathogenesis, diagnosis, and treatment. A literature review. Am J Orthod Dentofacial Orthop 2004;126(4):432-45.

35. Valmaseda-Castellón E, De-la-Rosa-Gay C, Gay-Escoda C. Eruption disturbances of the first and second permanent molars: results of treatment in 43 cases. Am J Orthod Dentofacial Orthop 1999;116(6);651-8.

36. Winter GB, Gelbier MJ, Goodman JR. Severe infraocclusion and failed eruption of deciduous molars associated with eruptive and developmental disturbances in the permanent dentition: a report of 28 selected cases. J Orthod 1997;24(2):149-57.

37. Wright $\mathrm{G}$, Welbury RR, Hosey MT. Cyclosporin-induced gingival overgrowth in children. Int J Paediatr Dent 2005;15(6):403-11. 